\title{
NUEVAS PERSPECTIVAS DE INVESTIGACIÓN DE LA FAMILIA ORCHIDACEAE EN COSTA RICA
}

\author{
Rafael Ángel Valverde Arias ${ }^{1} \&$ Adolfo Quesada Chanto ${ }^{2}$ \\ ${ }^{1}$ Fundación Orquídeas de Costa Rica. fundorqui-cr@terra.com
}

${ }^{2}$ Facultad de Microbiología, Universidad de Costa Rica y Fundación Orquídeas de Costa Rica. aqchanto@racsa.co.cr

Los aborígenes, primeros habitantes de nuestras tierras, tuvieron contacto directo con las bellas orquídeas que engalanaban las extensas selvas. Muestra de esto es la representación de algunas especies del género Oncidium en las denominadas "águilas de oro". Probablemente hicieron uso de algunas de ellas en el campo de la medicina.

Con el descubrimiento del continente americano y su posterior colonización, los europeos que vinieron a poblar Costa Rica se dieron cuenta de la vasta riqueza de orquídeas que aparecían creciendo sobre la tierra, las rocas y los árboles. Seguramente muchas especies sirvieron para embellecer sus rústicas viviendas.

Los primeros botánicos encontraron una forma perfecta de ocupar su tiempo. Más allá de observar sus diferentes formas vegetativas, aromas y colores, era de suma importancia darles un nombre que sirviera para diferenciar tal biodiversidad. Los primeros nombres fueron vulgares o populares, y con ellos trataron de destacar una característica sobresaliente que diferenciara unas especies de otras. Durante los siglos XVIII y XIX se gestó nuestro actual sistema taxonómico. A partir de entonces, se empezaron a crear en tierras americanas catálogos de especies y de información conocida hasta la fecha, lo cual propiciaba la existencia de una bibliografía incipiente. No obstante, las dificultades de transporte, disposición de material bibliográfico y de comunicación entre los botánicos pioneros que se dedicaron a estudiar nuestras orquídeas, propiciaron la aparición de nombres repetidos. Esto provocó la falsa noción de la existencia de un número mayor de especies con nombres que en realidad se referían a una sola.

Los esfuerzos para dotar de una lista de orquídeas a nuestro país se ven plasmados en las listas de Oakes Ames (1937) y de L.O. Williams (1956). Ambas listas incluían 959 especies en 133 géneros (GarcíaCastro \& Mora-Retana 1992). Pasaron los años, y aumentaba el números de especies atribuidas a Costa Rica. Finalmente, los eminentes orquideólogos costarricenses Dora Emilia Mora de Retana y Joaquín Bernardo García Castro publicaron una lista en la que recopilaban 1416 especies en 179 géneros (GarcíaCastro \& Mora-Retana 1992). Ellos creían que con la recolección de plantas para las flórulas regionales (La Selva, San Ramón, Monteverde, Parque Nacional Guanacaste, Parque Nacional Braulio Carrillo), con la descripción de especies para Icones Plantarum Tropicarum y con el estudio de géneros para la Flora Mesoamericana, el número superaría fácilmente las 1500 especies. Además, ellos trataron de evitar la duplicidad de nombres, actualizar los nombres de especies registradas y utilizar la nomenclatura correcta. Para los géneros o especies de nomenclatura controversial siguieron los criterios de autoridades orquideológicas que poseían amplio conocimiento de nuestras especies. Durante diez años esta lista fue utilizada como texto de consulta obligada por quienes deseaban desarrollar cualquier trabajo de la familia Orchidaceae en Costa Rica. Mientras tanto, cada año se describían nuevas especies que demostraban cuán vasta es la diversidad de orquidáceas en nuestro país. Robert L. Dressler, John T. Atwood, Carlyle L. Luer y Franco Pupulin, entre otros, han sido los responsables directos de tal enriquecimiento.

Lastimosamente, Mora-Retana y García Castro no dejaron un grupo fuerte de taxónomos que pudieran seguir con su delicado trabajo. Afortunadamente, años antes el investigador Franco Pupulin se dedicó a estudiar las orquídeas ticas y se propuso como objetivo revisar el material tanto bibliográfico como de herbario existente en Costa Rica y en otros países. Pupulin (2002a) publica el catálogo actualizado de orquídeas de Costa Rica, que se destaca por presentar testigos de cada especie, de tal manera que sólo considera válidas aquellas especies colectadas en el país que cuentan con un testigo en un herbario. Esta nueva lista incluye los últimos hallazgos de especies y excluye ciertos nombres aparecidos en el trabajo de García-Castro \& Mora-Retana (1992). 
La Fundación Orquídeas de Costa Rica planea continuar con el trabajo de Mora-Retana y García Castro, así como colaborar estrechamente con el Jardín Botánico Lankester y el investigador F. Pupulin. Los principales objetivos de dicha fundación son:

a. Identificar orquídeas presentes en Costa Rica.

b. Descubrir nuevas especies y variedades autóctonas de nuestro país.

c. Estimular el correcto cultivo y conservación de nuestras especies.

d. Promover la cuádruple interrelación: cultivo de orquídeas-ambiente integral-salud-longevidad.

e. Rescatar y reproducir orquídeas en peligro de extinción.

f. Estudiar y promover la reforestación de árboles nativos hospederos de nuestras orquídeas.

g. Monitorear las poblaciones de orquídeas, especialmente las que viven en ambiente inestables.

h. Producir material didáctico y audiovisual sobre la situación de las orquídeas en Costa Rica.

i. Promover la creación de bancos de germoplasma.

Los miembros de la Fundación trabajamos en la creación de una colección de flores en AFA (Pupulin 2002b), con la idea clara de complementar las colecciones vivas y así registrar la existencia de orquídeas no comunicadas ni documentadas o especies nuevas en nuestro país. También nos dedicamos a estudiar y proteger las orquídeas terrestres, porque sabemos que cerca del $20 \%$ de nuestra orquiflora pertenece a esta categoría, que ha sido poco estudiada, lo que genera grandes dificultades en su identificación. Aún más, algunas de éstas son poco llamativas, pasan frecuentemente inadvertidas para los colectores y pocas veces se encuentran presentes en colecciones. Desdichadamente, constituyen un grupo en peligro de desaparición, a pesar de no estar sometidas a la presión de recolección masiva, dado que, al igual que las epífitas, sufren el impacto de la deforestación, el exterminio por incendios forestales y el uso indiscriminado de agroquímicos, cuando crecen entre o muy cerca de cultivos tradicionales. Para tal efecto, se realizan excursiones de campo para colectar flores de estas especies. Así es como hemos colaborado en el hallazgo del género Aulosepalum en Costa Rica y en la detección de importantes poblaciones de otras orquídeas terrestres, tales como Stenorrhynchos millei.

Felizmente, nos esforzamos por continuar con el legado heredado de nuestros grandes orquideólogos; Rafael Lucas Rodríguez Caballero, Dora Emilia Mora de Retana y Joaquín Bernardo García Castro. Seremos parte del trabajo de estudio y identificación de la flora orquidácea de Costa Rica, que el Jardín Lankester realiza desde muchos años. Asumimos como un objetivo prioritario la conservación de especies escasas y raras.

Representamos un grupo de nuevos investigadores costarricenses. Deseamos trabajar arduamente por nuestro país. Pensamos que no hacer nada por rescatar la riqueza de la flora orquidácea de Costa Rica se constituiría en un grave acto de culpabilidad que no queremos cargar sobre nuestras espaldas. ¡Cumplamos con nuestra responsabilidad para honrar nuestro bello y fecundo país!

\section{Literatura CitADA}

García-Castro, J.B. \& D.E. Mora-Retana. 1992. Lista actualizada de las orquídeas de Costa Rica (Orchidaceae). Brenesia 37:79-124.

Pupulin, F. 2002a. Catálogo revisado y anotado de las Orchidaceae de Costa Rica. Lankesteriana 4: 1-88.

Pupulin. F. 2002b. "Flores inmortales": colecciones en alcohol en el JBL. Epidendrum 21:2.

Smith, F., C.A. Villée \& W.F. Walker Jr. 1970. Zoología. Nueva Editorial Interamericana. México.

Rafael Ángel Valverde Arias es biólogo naturalista con estudios realizados en la Universidad de Costa Rica. Desde 1992 es estudioso de las orquídeas del país. Es miembro de la Asociación Costarricense de Orquideología (ACO) y de su Comité de Juzgamiento. Fue discípulo de Dora Emilia Mora de Retana y Joaquín Bernardo García Castro. Es Presidente y fundador de la Fundación Orquídeas de Costa Rica.

Adolfo Quesada Chanto es Licenciado en Microbiología y Química Clínica de la Universidad de Costa Rica. Tiene un Doctorado en Bioquímica y Biotecnología de la Universidad de Braunschweig, Alemania Federal, y varios posdoctorados. Ha publicado más de 20 artículos científicos, es autor y coautor de varios libros en el área de la biotecnología y ha participado como expositor en numerosos congresos. Es profesor de pre y posgrado en dos universidades de Costa Rica, Director de Cátedras de Bioquímica Clínica, Bioquímica General y Biotecnología. 